\title{
Dynamics of the Scale and Its Natural Enemies in a Citrus Grove at Ceiba, Cuba
}

\author{
Tamara Awerbuch-Friedlander ${ }^{1}$, Caridad Gonzalez ${ }^{2}$, Doris Hernandez ${ }^{2}$, Richard Levins ${ }^{1}$, Sonja Sandberg ${ }^{3}$, \\ Jorge Ricardo Sibat ${ }^{2} \&$ Jorge Luis Tapia ${ }^{2}$ \\ ${ }^{1}$ Department of Global Health and Population, Harvard School of Public Health, 655 Huntington Ave., Boston, \\ MA 02115, USA \\ ${ }^{2}$ Instituto de Investigaciones de Citricos Ave. 23 \#22816 e222 y 234 La Coronela, Playa, C. Habana Cuba \\ ${ }^{3}$ Department of Mathematics, Framingham State University, 100 State Street, Framingham, MA 01701, USA \\ Correspondence: Tamara Awerbuch-Friedlander, Department of Global Health and Population, Harvard School of \\ Public Health, 655 Huntington Ave., Boston, MA 02115, USA. Tel: 1-617-432-2505. E-mail: \\ tamara@hsph.harvard.edu
}

Received: March 8, 2013 Accepted: May 25, 2013 Online Published: August 15, 2013

doi:10.5539/jas.v5n9p6 URL: http://dx.doi.org/10.5539/jas.v5n9p6

\begin{abstract}
Aim: Research was conducted to study the population dynamics of a citrus scale, and its parasites in "Empresa de Citricos de Ceiba", Havana Province, Cuba. Orange trees, Glover's scale Lepidosaphes gloverii (coccidae, homoptera), and four of its natural enemies including three fungi and a parasitic wasp, were studied in their distributions in space and time, and their interactions, in order to understand why this scale is not a serious pest in Cuba. Methodology: The study consists of observations made bi-weekly on the site during an entire year. Various statistical analyses including Taylor regression and new probabilistic methods that were developed for this study were used to explore the mechanisms of natural regulation of the pest. Major findings: The results of the analysis showed that the scale population was kept in check by seasonally varying recruitment and by mortality that was density dependent through gradual parasitization by several species with distinct spatial preferences and some overlapping. The findings also showed that the first natural enemy to settle on the scale did so independently of the number of scales on the leaf; but ones this happens there was contagion within the scales on the leaf. Conclusion: The study demonstrates that the pest can be regulated within an ecological context of community dynamics. A general theoretical result based on loop analysis demonstrates that using pesticides to control agricultural pests where they co-exist with their natural enemies would actually have counterproductive results, in fact increasing the pest.
\end{abstract}

Keywords: ecological control, seasonality, agricultural pests, citrus, fungi, wasp, parasitization, natural enemies

\section{Introduction}

Community ecology is increasingly dynamic. It has to deal with the changing populations of species where both the impact of the external physical environment and the impact of the mutual interactions are essential. This is particularly relevant in agriculture where the crop and its invading pests become part of the natural ecosystem. Thus, research was conducted to study the population dynamics of the Glover's scale Lepidosaphes gloverii (coccidae, homoptera) (Metcalf \& Flint, 1962) and its parasite on citrus leaves. The orange trees, the scales themselves at their developmental stages, and four natural enemies including three fungi and a parasitic wasp were studied in their distributions in space and time, and their interactions in order to determine the mechanisms of population regulation in the context of a multi species community.

The old debates between "environmental" determination (Andrewartha \& Birch, 1954) and density dependent regulation as espoused by Nicholson and Bailey (Nicholson \& Bailey, 1935) have been replaced by the recognition that both are operative simultaneously (Price, 1991). Density dependent interactions determine how the statistical distribution of numbers responds to external perturbation even when numbers are far from equilibrium. External inputs percolate through the networks of interactions to determine how density-dependent processes can be driven from outside. The correlation patterns among species depends on which species the external conditions impact directly (Levins \& Schultz, 1996). Density-dependent processes can determine the probabilities of movement 
among micro-habitats and therefore the environments to which species are exposed. The availability of resources as influenced by density and the physical environment can determine the nutritional status of organisms, body size and therefore how they respond to the physical environment and how mobile they are. The environment may determine the outcomes of aggressive and competitive interactions. Environmentally sensitive "weak determination" (Strong, 1989) still reflects the interaction pattern and is quite different from autonomous responses to the environment. Even when conditions become extremely harsh and resources dry up or freeze independently of the species densities, the probabilities of survival of individuals are influenced by the previous interactions, and the total survival responds to the numbers.

The citrus scale is useful for the study of community dynamics. After the brief crawler stage, the subsequent stages (except for the adult males) are sessile, so that different trees and sections of trees can be examined as distinct populations in distinct microhabitats. The long generation time (more than two months) (Metcalf et al., 1962) allows us to track populations with biweekly observations. Broken scales are retained on the leaf as evidence of predation while parasitized scales can be identified as to parasite. The number of scales in different life stages, their distribution over seasons and microhabitats, the intensity of aggregation and the correlated spatial-temporal variation of the natural enemies allow us to interpret the observed pattern both as density-dependent (non-linear) and environmentally responsive.

Biodiversity is considered essential for maintaining the health of agroecosystems (Altieri, 1999). The expansion of agricultural land led to the loss of non-crop habitats resulting in a decline of biodiversity needed to preserve natural enemies of agricultural pests (Bianchi, Landis, \& Wilby, 2006).

For the first time a holistic ecological analysis is developed to demonstrate that control of agricultural pests takes place within a context of a community of natural enemies that share they prey by invading at different seasons and differing in their spatial distribution. Moreover this work presents novel mathematical approaches to understand the mechanisms of regulation.

\section{Materials and Methods}

\subsection{The Site and the Environment}

The field work was carried out at the Empresa de Citricos de Ceiba, located $17.5 \mathrm{~km}$ northeast of Artemisa, Havana Province, Cuba at an average elevation of 80 meters. The average temperature was $24.9^{\circ} \mathrm{C}$, ranging from an average minimum of $14.6^{\circ} \mathrm{C}$ in the coldest month (February) to an average maximum of $31.2^{\circ} \mathrm{C}$ in the hottest month (July). Annual precipitation averaged $1505 \mathrm{~mm}$ over a ten-year period. The region has karst topography with protrusions of bare limestone and a red ferralitic soil varying from depths of less than $2 \mathrm{~cm}$ to $100 \mathrm{~cm}$. The yield of oranges averaged $113.3 \mathrm{~kg} /$ tree. The major pests of citrus on this farm were rust mites and two species of curculionid, with thrips, aphids, and a few other coccids and mites having minor importance.

\subsection{Data Collection}

Biweekly observations were made on five trees of Valencia oranges following flushes during 1986, resulting in a collection of 4740 data points which enabled the study of scale dynamics through many cycles of population growth. Five trees were selected and numbered as follows: trees 1-4 were located at the corners of a field and tree 5 was in the middle. For each tree, branches were selected at each of four different cardinal points (N, S, E, W) and three different strata defining levels of height above the ground $(1,2,3)$. Two leaves from a recognizable flush were chosen at random from each tree, at each cardinal point and at three strata levels, resulting in a minimum of 120 leaves examined on each date. As the season progressed and more leaves developed, then the other leaves in that flush were also identified and examined. On each branch, leaves were numbered starting at 1 for the one closest to the trunk. Leaves numbered " 0 " are leaves without scales and their location along the stem was not recorded. The upper and lower surfaces of each leaf were examined for scales and natural enemies. The scales were counted on the leaf and classified visually as to stage of development: crawlers, nymphs or seconds, pre-adult females, females with eggs, and males. Parasitized scales were identified as having infections of Sphaerostilbe auranticola (HR), Podonectria cocciola (HB), a third unspecified internal fungus (HI), and the wasp Aspidiotiphagus sp (chalcid) (PI). Infected scales could not be identified as to stage.

\subsection{Analytical Methods}

Data were analyzed using EPI Info version 6, a non-proprietary program prepared by the Center for Disease Control (A. Dean, J. Dean, Burton, \& Dicker, 1990) and Lotus 1-2-3 (Lotus Development Corp., 1988). 


\subsubsection{Distribution of Leaves in Space and Time}

Contingency tables were constructed to compare the numbers of leaves on different trees, strata, and cardinal points and over time; chi-square statistics were used to test statistical significance. The number of collected leaves is an indicator of the condition of the tree since numbers above the basic 24 per tree reflect the balance between new leaves on a twig and leaf fall.

\subsubsection{Distribution of Scales and its Natural Enemies in Space and Time}

Distribution of scales and its four natural enemies, across leaves at the various positions along the branch, was determined by calculating the mean number of scale per leaf for a particular position. Contingency tables were constructed to compare the numbers of scales on different trees, strata, cardinal points, upper and lower leaf surfaces over time; chi-square statistics were used to test statistical significance.

\subsubsection{Taylor's Regression to Study Aggregation}

Taylor (Taylor, Woiwod, \& Perry, 1978) proposed that aggregation of living organisms be described by the exponent $b$ in the relationship:

$$
\mathrm{V}=\mathrm{a} \mathrm{M}^{\mathrm{b}}
$$

where $\mathrm{M}$ and $\mathrm{V}$ are the mean and variance of the numbers in different sites. A random distribution would show the Poison value of $b=1$; a more uniform distribution would have $b<1$ while aggregation would show up in values of $\mathrm{b}>1$. This method was previously used to compare aggregation in other scale populations in Israel (Nestel, Cohen, Saphir, Klein, \& Mendel, 1995). The following logarithmic form was used for the analysis:

$$
\log \mathrm{V}=\log \mathrm{a}+\mathrm{b} \log \mathrm{M}
$$

The estimates of $\mathrm{M}$ and $\mathrm{V}$ over time and space were obtained from data analysis carried out with Epi-Info. The parameter $b$ was estimated with linear regression based on equation (2) using Lotus 1-2-3.

\subsubsection{Crawler Migration}

The crawlers are the first developmental stage after the eggs hatch and the only immature one which is not sessile. Indeed, many of the crawlers are found on leaves without females with eggs. A model to assess migration was developed as follows: suppose that movements were at random, and that the fraction $\mathrm{pc}$ of the crawlers exit from the leaf on which they were born. Since the fraction $\mathrm{pl}$ of the other leaves has females with eggs, $p_{c} p_{1}$ of the crawlers would move to other leaves with females with eggs and (1- $\left.p_{l}\right) p_{c}$ would reach leaves without them. Then $\mathrm{p}_{\mathrm{c}}$ could be estimated by:

$$
\mathrm{p}_{\mathrm{c}}=\mathrm{x} /\left(1-\mathrm{p}_{1}\right)
$$

where $\mathrm{x}$ is the fraction of the crawlers found on leaves without fecund females and an average of 1-pc of the crawlers remain on their birth leaves. This calculation does not take into account migration from leaves to stems or fruit.

\subsubsection{Reproduction}

It is not possible to measure fecundity directly by counting eggs. Therefore crawlers were counted as the first stage of life. Since crawlers live for only a day, the ratio of crawlers to fecund female (with eggs) it approximately estimates fecundity. This may not be a true fecundity since the crawlers experience high mortality during their one day of life (Greathead, 1990). In the analysis the ratio of crawlers to fecund females was used as a measure of reproduction.

Another estimate of reproduction can be obtained taking advantage of the knowledge of migration: Let $p_{c}$ be the fraction of the crawlers that exit from the leaf on which they were born, as previously defined. The probability that all $n$ crawlers that were born to a particular female leave the site of birth is $p_{c}{ }^{n}$, and to $k$ females is $p_{c}{ }^{k n}$. Let $r$ be the probability that no crawlers enter the site of fertile females. Thus the probability of finding no crawlers on a leaf with one fertile female is $\mathrm{q}_{1}=\mathrm{r} \mathrm{p}_{\mathrm{c}}{ }^{\mathrm{n}}$, and for $\mathrm{k}$ females is $\mathrm{q}_{\mathrm{k}}=\mathrm{r} \mathrm{p}_{\mathrm{c}}{ }^{\mathrm{kn}}$. The ratio $\mathrm{q}_{\mathrm{k}} / \mathrm{q}_{\mathrm{k}-1}=\mathrm{p}_{\mathrm{c}}{ }^{\mathrm{n}}$ and can be estimated from the data. Knowing $p_{c}$ enables the estimation of $n$, the number of crawlers born to one female:

$$
\mathrm{n}=\left[\log \left(\mathrm{q}_{\mathrm{k}} / \mathrm{q}_{\mathrm{k}-1}\right)\right] / \log \mathrm{p}_{\mathrm{c}}
$$

\subsubsection{Probability of Infection}

Let $\mathrm{p}_{\mathrm{i} 1}$ be the probability that a propagule of a fungus, or a foraging wasp from outside a leaf finds a host on a leaf with non-parasitized scales. Suppose that there are $\mathrm{n}$ uninfected scales on the leaf. Then the probability $\mathbf{y}$, of missing all of them is $\left(1-p_{i 1}\right)^{n}$ and the probability $p_{i 1}$ of a unit propagule finding a scale is estimated by

$$
\mathrm{p}_{\mathrm{i} 1}=1-\mathrm{y}^{(1 / \mathrm{n})}
$$


where $\mathrm{y}$ is the fraction of leaves with $\mathrm{n}$ scales, none of them infected.

Let $\mathrm{p}_{\mathrm{i} 2}$ be the probability of a second scale becoming infected conditional on there being one infected on the same leaf. Then $1-p_{i 2}$ is the probability that this does not happen, $\left(1-p_{i 2}\right){ }^{n-1}$ is the probability that none of the other scales are infected. Therefore $\mathrm{p}_{\mathrm{i} 2}$ can be estimated for each $\mathrm{n}$ by:

$$
\mathrm{p}_{\mathrm{i} 2}=1-\mathrm{z}^{(1 /(\mathrm{n}-1))}
$$

where $\mathrm{z}$ is the fraction of leaves with $\mathrm{n}$ scales that have only one infected scale. The same rationale is used for estimating the probability that a third or a fourth scale becomes infected conditional on there being one less infected scale.

\section{Results}

\subsection{Leaf Distribution}

The number of leaves varied across dates reflecting the seasonality of leaf growth, peaking in the fall (Figure 1). The five trees differed significantly in the numbers of leaves collected, an indicator of the vigor of growth. The tree numbered one had the highest proportion of total leaves collected. The percentage decreased with tree number: $24.4 \%, 22.7 \%, 18.5 \%, 17.6 \%$, and $16.9 \%$ [Chi-Square $=105.37 \mathrm{df}=4$, P-value $<0.005]$. They are ranked in inverse numerical order, with tree one having some 50\% more leaves on flushes than tree 5 , located at the center of the grove. Regression of number of leaves across trees showed a significant correlation with tree number: $\mathrm{R} 2=91.2 \%$, P-value $=0.011$. This correlation might have been an artifact of the collection, choosing perhaps the healthiest trees first.

There was no significant difference in distribution of leaves across strata: $34.5 \%, 32.4 \%$, and $33.0 \%$ [Chi-Square $=3.10, \mathrm{df}=2$, P-value $>0.10]$. There was no significant difference in the distribution of leaves across cardinal points: $26.2 \%, 24.8 \%, 24.4 \%$, and $24.5 \%$ for North, South, East and West respectively. [Chi-Square $=4.03$, df $=$ 3 , P-value $>0$.10].

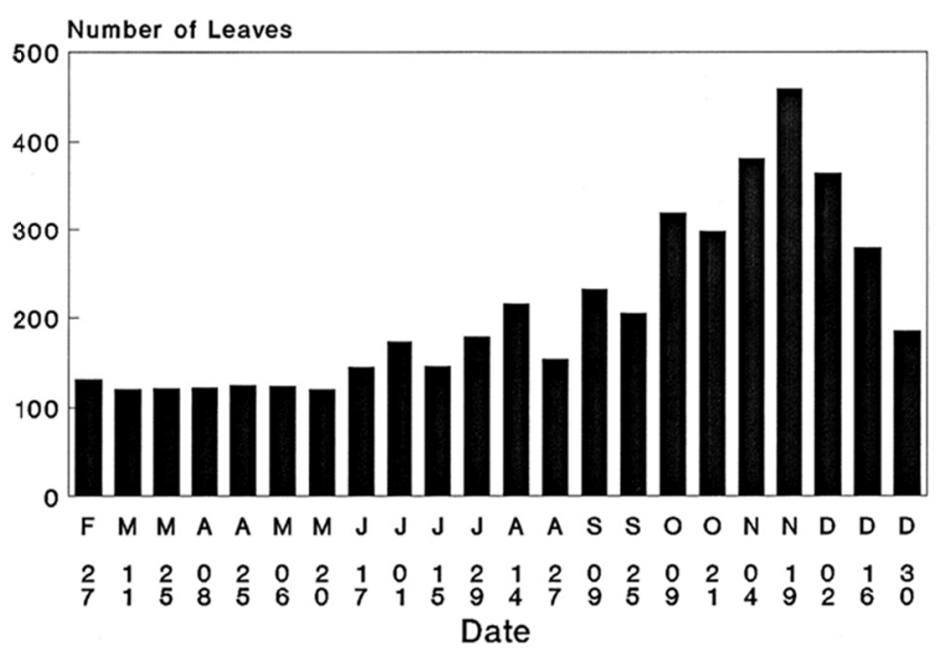

Figure 1. Seasonal distribution of leaves

\subsection{Spatial Distributions of Scales and Parasites}

The scales and their parasites are distributed over different trees, cardinal points, strata in the canopy, leaf position along a branch, and the upper and lower surfaces of leaves.

\subsubsection{Distribution of Scales and Parasites Over Trees}

Overall, $61 \%$ of the flush leaves had scales, but the distribution was not uniform across trees. Leaves that had scales on them were most likely to be found on tree number 1 . This fraction decreased with tree number: $74.6 \%$, $70.2 \%, 63.9 \%, 57.9 \%$ and $54.6 \%$. This trend is similar to the one observed on leaf abundance on trees. The mean number of live scales per leaf was highest on tree number 1 and decreased with tree number, again following the same pattern of leaf abundance: $1.97,1.76,1.72,1.38$ and 0.86 (F statistic $=24.825$; P-value $<0$.0000001). The same decreasing trend was observed when parasitized scales were included in the analysis. The observed correlation between scale and leaf abundance lead to the exploration of the possibility that higher scale fecundity, 
as a result of feeding on a healthier tree, might be the reason for the observed uneven abundance of scales. However no significant difference in scale fecundity was detected among trees (see section on reproduction).

When parazitisation rates were examined a different picture emerged. Only 37.7\% (2690 parasites/7140 total number of scales at their sessile stages; excluding males and crawlers) were infected. Table 1 shows the rates of parasite infection per scale across trees. There are significant differences among trees, with tree 5, which is in a protected position in the middle of the orchard, having the highest overall rate of fungal infection and a low rate of parasitism by wasps. However the other trees were not in rank.

Table 1. Mean number of parasites per scale on different trees

\begin{tabular}{cccccc}
\hline & \multicolumn{5}{c}{ Tree } \\
\cline { 2 - 6 } & 1 & 2 & 3 & 4 & 5 \\
\hline Parasite & & & & & \\
$P C$ & 0.019 & 0.041 & 0.051 & 0.042 & 0.058 \\
$M D$ & 0.013 & 0.016 & 0.019 & 0.021 & 0.035 \\
$S A$ & 0.282 & 0.164 & 0.195 & 0.174 & 0.336 \\
$A S P I$ & 0.056 & 0.101 & 0.106 & 0.103 & 0.064
\end{tabular}

$\mathrm{PC}=$ PC Podonectria coccicola;

$\mathrm{MD}=$ Myrianguium duriaei Monty Berk and the wasp;

$\mathrm{SA}=$ Sphaerostilbe auranticola;

ASPI $=$ Aspidiotiphagus sp.

\subsubsection{Distribution of Scales Across Leaf Position}

Although there were differences among $t$ leaves at various positions along the twig in providing a habitat for scales, with leaves numbered three being most abundant (Figure 2), this difference did not seem to be statistically significant (Chi-Square $=53.86, \mathrm{df}=49, \mathrm{P}$-value $=0$.7062).

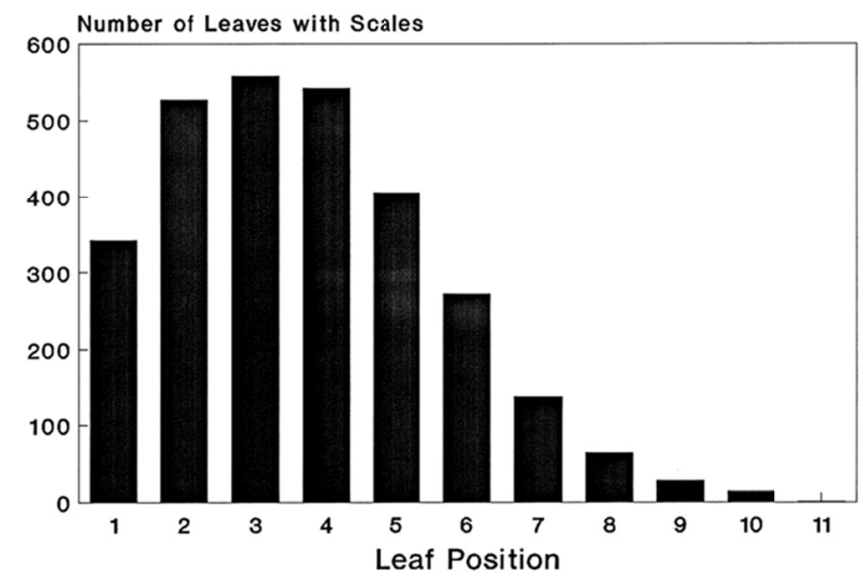

Figure 2. Scale abundance across leaf position

Table 2 shows the mean number of scales per leaf as a function of leaf position along the twig. The grand mean was 3.1 scales on leaves with scales. There is a slight indication that leaves in the central part of the twig (positions 3-6) had more scales. No significant difference (Kruskal- Wallis $\mathrm{H}=16.66$, df $=10, \mathrm{P}$-value $=0.08$ ) was observed in distribution of the number of scales across leaf number (age of leaf) probably due to the fact that scale do not prefer younger leaves over old ones or because older leaves had been longer exposed to possible scale infestation. 
Table 2. Mean number of scales across leaf position

\begin{tabular}{cc}
\hline Leaf number & Mean number of scale \\
\hline 1 & $2.59 \pm 2.81$ \\
2 & $2.88 \pm 3.09$ \\
3 & $3.55 \pm 4.06$ \\
4 & $3.25 \pm 4.02$ \\
5 & $3.15 \pm 3.74$ \\
6 & $3.14 \pm 3.82$ \\
7 & $2.58 \pm 2.03$ \\
8 & $2.67 \pm 2.71$ \\
9 & $3.14 \pm 2.02$ \\
10 & $2.43 \pm 2.34$ \\
\hline
\end{tabular}

\subsubsection{Distribution of Scales over Surface of Leaf}

On the upper surface there were more observations than on the lower surface of the leaves which might have changed the overall distribution. Thus, dates were examined where the number of observations was the same on both surfaces (May 6 and 20) and found that there was no difference in scale distribution between these two dates and all other dates, indicating that the different number of observations will not alter the overall results. The upper surface of a leaf is preferred by scales. The ratio of the number of scales per leaf between the upper and lower surface of the leaf is highest for crawlers, and decreases as the scale progresses through the stages (Table 3). On the upper surface there are more fungi per scale than in the lower surface of the leaf. However there is a slight preference by the wasp to choose the lower surface. In general there is a higher parasitization rate on the upper surface (Table 4).

Table 3. Mean number of scales per surface of leaf

\begin{tabular}{lccccc}
\hline & Crawlers & Nymphs & Females & Feggs & Males \\
\hline Upper & $0.529 \pm 1.365$ & $0.725 \pm 1.358$ & $0.292 \pm .759$ & $0.194 \pm .509$ & $0.329 \underline{+0 .} .854$ \\
Lower & $0.128 \underline{+0.568}$ & $0.270 \underline{+0.727}$ & $0.133 \underline{ \pm 0.510}$ & $0.091 \pm \underline{0 .} .379$ & $0.162 \underline{+0.576}$ \\
Ratio & 4.13 & 2.69 & 2.20 & 2.13 & 2.03 \\
\hline
\end{tabular}

Table 4. Mean number of parasites per scale on upper and lower surfaces

\begin{tabular}{lllll}
\cline { 2 - 5 } & & \multicolumn{3}{c}{ Leaf Surface } \\
\cline { 2 - 5 } & & Lower & Upper & Ratio \\
\cline { 2 - 5 } & Parasite & & & \\
& $P C$ & 0.015 & 0.044 & 2.93 \\
& $M D$ & 0.021 & 0.030 & 1.43 \\
& $S A$ & 0.188 & 0.234 & 1.24 \\
& ASPI & 0.098 & 0.082 & 0.84 \\
PC = PC Podonectria coccicola $;$ & All parasites & 0.322 & 0.389 & 1.21 \\
\cline { 2 - 5 } $\mathrm{MD}=$ Myrianguium duriaei Monty & Berk and the wasp; & & \\
$\mathrm{SA}=$ Sphaerostilbe auranticola $;$ & & & & \\
$\mathrm{ASPI}=$ Aspidiotiphagus sp. & & & &
\end{tabular}




\subsubsection{Distribution of Scales Over Strata}

There was no significant differences in the mean number of live scales per leaf across strata (1.4, 1.2 and 1.3 for strata number 1, 2, and 3, Kruskal-Wallis H P-value $=0.074$ ). However there was a statistically significant difference if parasitized scales were included in the analysis $(2.1,1.7$ and 1.8 for strata number 1, 2, and 3 respectively, Kruskal-Wallis $\mathrm{H}$ P-value $=0.026$ ). This small differences in means while statistically significant might not be biological meaningful. Parasitization rates are different across strata: HB and HI prefer the middle section, HR prefers 1 and the wasp prefer 3 (Table 5).

Table 5. Mean number of parasites per scale at different strata

\begin{tabular}{|c|c|c|c|c|}
\hline & & \multicolumn{3}{|c|}{ Strata } \\
\hline & & 1 & 2 & 3 \\
\hline & \multicolumn{4}{|l|}{ Parasite } \\
\hline & $P C$ & 0.032 & 0.044 & 0.041 \\
\hline & $M D$ & 0.023 & 0.040 & 0.023 \\
\hline & $S A$ & 0.270 & 0.209 & 0.190 \\
\hline & $A S P I$ & 0.062 & 0.080 & 0.115 \\
\hline $\mathrm{C}=\mathrm{PC}$ Podonectria coccicola & & & & \\
\hline $\mathrm{MD}=$ Myrianguium duriaei Mont $y$ & $r k$ and the & wasp; & & \\
\hline $\mathrm{SA}=$ Sphaerostilbe auranticola & & & & \\
\hline $\mathrm{SPI}=$ Aspidiotiphagus $\mathrm{sp}$ & & & & \\
\hline
\end{tabular}

\subsubsection{Distribution of Scales Over Cardinal Point}

The scales start their lives as crawlers preferring to settle in some directions over others (mean numbers per leaf: $0.459,0.388,0.423$, and 0.237 for North, South, East and West respectively, Kruskal-Wallis H P-value $=$ $0.000013)$. The location of the scale foci is determined by the crawlers because the subsequent stages are sessile. There was a significant difference in the mean number of live scales per leaf across cardinal point $(1.6,1.3,1.4$ and 1.0 for North, South, East, West respectively, Kruskal-Wallis H P-value $=0.000023$ ). This has the same ordering as the one for crawlers.

However no significant difference was found when parasitized scales were included in the analysis along with the live ones $(2.2,1.8,2.0$ and 1.6 for North, South, East and West respectively, Kruskal-Wallis H P-value $=0.11$ ). While scales themselves might not prefer one location over the other, as they get parasitized more survivors will be found on the North surface and fewer on the West side of the tree. An analysis of parasitization rate on each of the directions found that in general the fungi preferred scales on the west side while this side was least preferred by wasps and the scales themselves as determined by the crawlers (Table 6).

Table 6. Mean number of parasites per scale in different directions

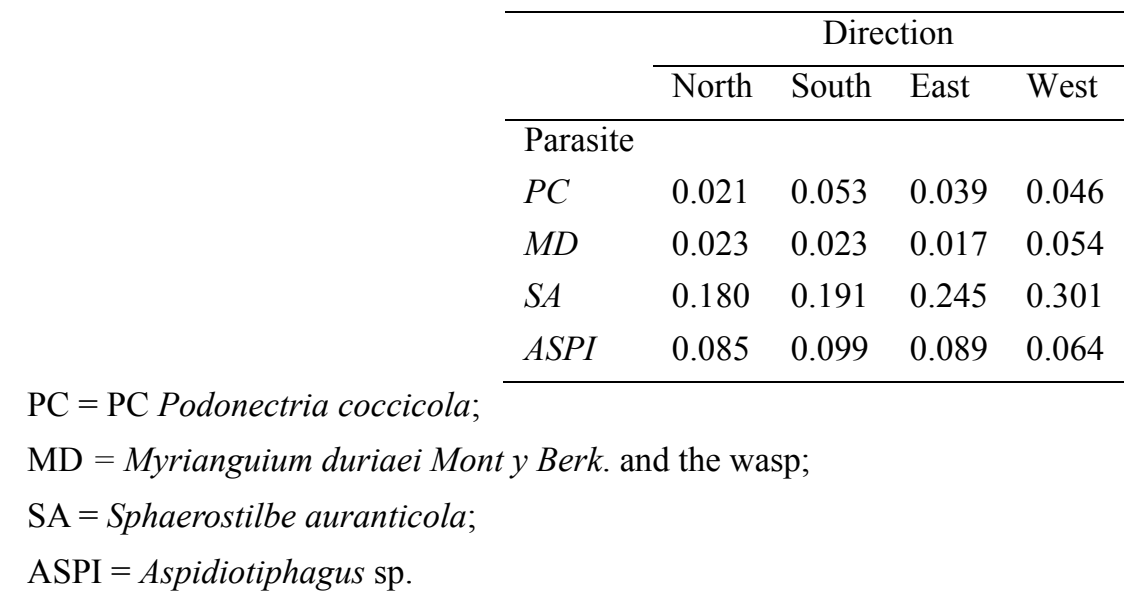




\subsection{Seasonal Patterns of Scale and Parasite Distributions}

Figure 3 shows the seasonal distribution of live scales at their various developmental stages. Scales are rare on the leaves of Valencia oranges until late spring, increase to a peak in mid-autumn and then decline again. The three fungi and the wasp parasitize the sessile stages of scale. They appear after a delay of a few months.

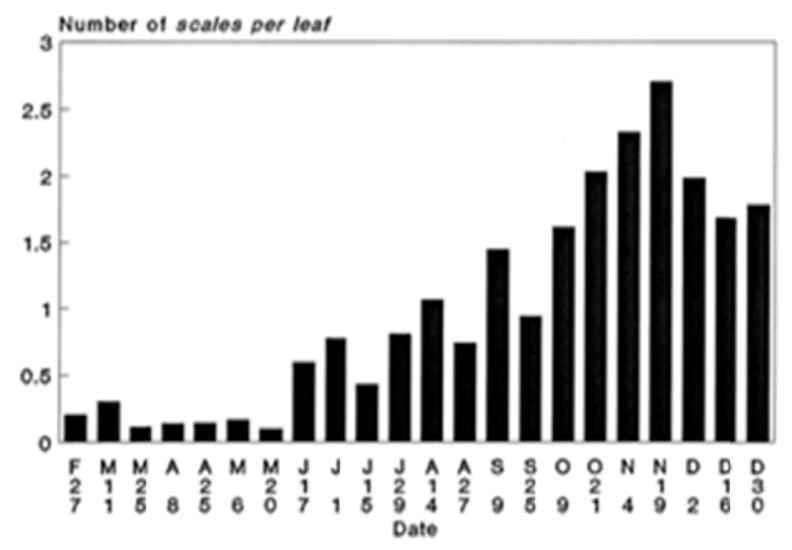

Figure 3. Seasonal distribution of scales

Sphaerostilbe invades in two waves, the first in early spring and the second in late summer, with the main peak in the fall. The unidentified fungus appears in late summer and peaks in mid fall. The wasp Aspidiotiphagus sp. and Podonectria coccicola were found only during the months of November and December. The rates of parasites per scale throughout the months of the year are presented in Figures $4 \mathrm{a}-4 \mathrm{~d}$.

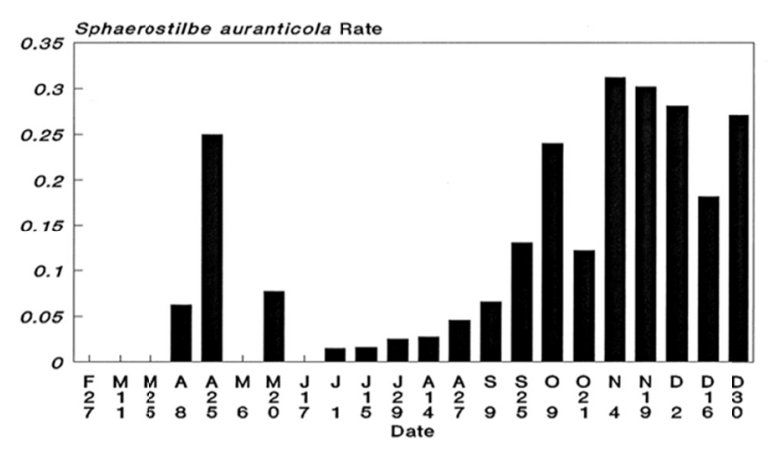

Figure 4a. Parasitization rates across dates

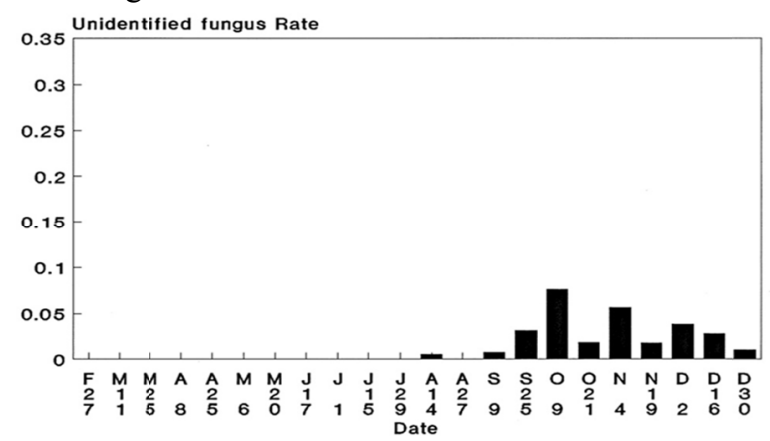

Figure 4c. Parasitization rates across dates

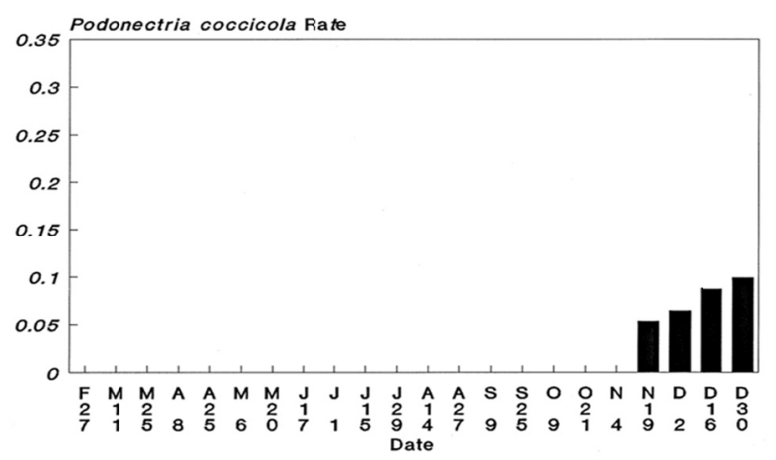

Figure 4b. Parasitization rates across dates

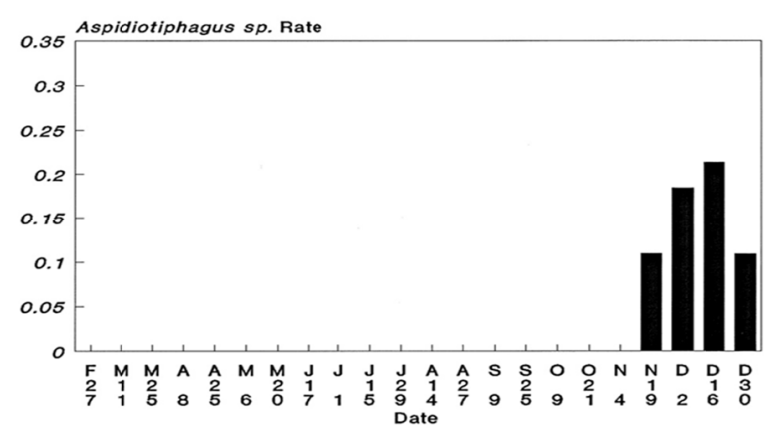

Figure 4d. Parasitization rates across dates 


\subsection{Emergence of New Foci}

The formation of new communities of scales depends on the migration of crawlers since they are the only mobile immature stage. Using Equation (3), it is possible to estimate the proportion of crawlers that leave the site of birth to start up new communities. Migration varied slightly from tree to tree with a mean of 0.8 (Table 7).

Table 7. Crawler migration using Equation (3) in text

\begin{tabular}{llllll}
\hline & Tree 1 & Tree 2 & Tree 3 & Tree 4 & Tree 5 \\
\hline X(cr w/o feggs) & 0.700 & 0.650 & 0.660 & 0.704 & 0.799 \\
$\mathrm{p}_{\mathrm{l}}$ (leaves w feggs) & 0.146 & 0.165 & 0.142 & 0.065 & 0.069 \\
$\mathrm{p}_{\mathrm{c}}$ (migration) & 0.817 & 0.778 & 0.769 & 0.769 & 0.858 \\
\hline
\end{tabular}

$\mathrm{f}_{\text {eggs }}=$ fertile females; $\mathrm{p}_{1}=$ proportion of leaves with feggs;

$\mathrm{p}_{\mathrm{c}}=$ proportion of crawlers that migrate out fraction of the crawlers;

$\mathrm{X}=$ fraction of the crawlers found on leaves without fecund females.

\subsection{Reproduction}

Reproduction estimated using Equation (4) and the complete set of data is found to be 1.86 crawlers per female. With this method it is impossible to calculate fecundity on particular dates because of the small sample size. Reproduction estimated by the ratio between crawlers and fertile females show an oscillatory pattern and ranges between 0.1 to 6.8 depending on the season (Figure 5). An analysis for individual trees showed a similar seasonal pattern for scale reproduction with a mean, varying around 2.6 crawlers per female with eggs.

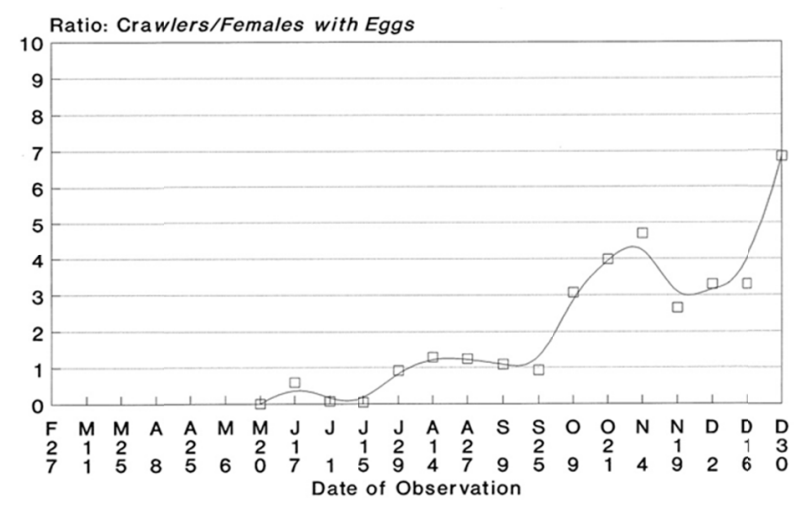

Figure 5. Seasonal fecundity

\subsection{Aggregation}

The mean number of scales per leaf changes over time and so does its variance. From the relationship between the two, one can explore the extent of aggregation. A regression line based on equation 2 for all stages (excluding the males because of their high mobility), indicates that there was aggregation in all cases since the coefficient $b$ is greater than 1. However the degree of aggregation is greatest for crawlers $\left(b_{\text {craw }}=1.33\right)$ and decreases with stage $\left(b_{\text {nymph }}=1.27, b_{\text {females }}=1.14 b_{\text {fer-fem }}=1.04\right)$, indicating that the immature stages are more aggregated and some aggregation is being lost along the developmental course.

We carried out the same analysis of the Taylor regression to explore the possibility that parasites might affect aggregation. The regression coefficient, $b$, of the regression line for the total number of live scales (excluding males) was compared with the one for the total number of live and parasitized scales. In both cases the coefficient of regression was $1.47 ; \mathrm{SE}=0.06, \mathrm{R} 2=.97$. This falls in the range of 1.3 to 1.9 , characteristic of other scales (Nestel, Cohen, Saphir, Klein, \& Mendel, 1995). In order to explore the effect of crawlers on the general pattern of aggregation, a similar analysis was conducted after subtracting the crawlers from the total number of scales and obtained the same result that aggregation across dates is not affected by the presence of parasites (coef. $=1.4$; $\mathrm{SE}=$ 0.06 ; $\mathrm{R} 2=0.96$ ). Parasites do not effect aggregation for total numbers of scales, with or without crawlers (Table 
8a). One explanation for the non-effect of parasites is that they were too rare on most dates to have any noticeable effect (Figure 4). However the crawlers will have some effect on aggregation whether the parasites are included or excluded in the analysis.

Table 8a. Taylor regression coefficient, b, across dates

\begin{tabular}{lll}
\hline & With crawlers & Without crawlers \\
\hline With parasites & $1.471+.050$ & $1.384+.060$ \\
Without parasites & $1.474 \pm .057$ & $1.364_{ \pm} .067$ \\
\hline
\end{tabular}

Table 8b. Taylor regression coefficient, b, across leaves

\begin{tabular}{lll}
\hline & With crawlers & Without crawlers \\
\hline With parasites & $2.676_{ \pm}^{+.43}$ & $2.743_{ \pm} .57$ \\
Without parasites & $1.401_{ \pm} .66$ & $1.450 \pm .50$ \\
\hline
\end{tabular}

Exploring aggregation across leaves gave the opposite result (Table 8b): The parasites had an effect on aggregation while the crawlers had none. This difference in aggregation effect of the crawlers across date vs. leaf is due to the fact that the crawlers are born in an aggregated state; the fertile females are immobile and lay the eggs in one place. The effect of time is eliminated when the analysis is carried out across leaves.

Aggregation takes on importance in relation to density-dependent regulation. It will be shown below that the probability of being parasitized increases with the number of scales on a leaf. The fraction of parasitized scales that share their leaves with other scales increases with population density so that mortality increases with density.

\subsection{Probabilities of Parasitic Infections of Scales}

The parasitization rate, the fraction of scales that have parasites, is proportional to the density of scales on leaves (Figure 6). This rate can be interpreted as the probability that one scale is infected by a parasite. Observations indicate that there are more parasites per scale as density of scale increases.

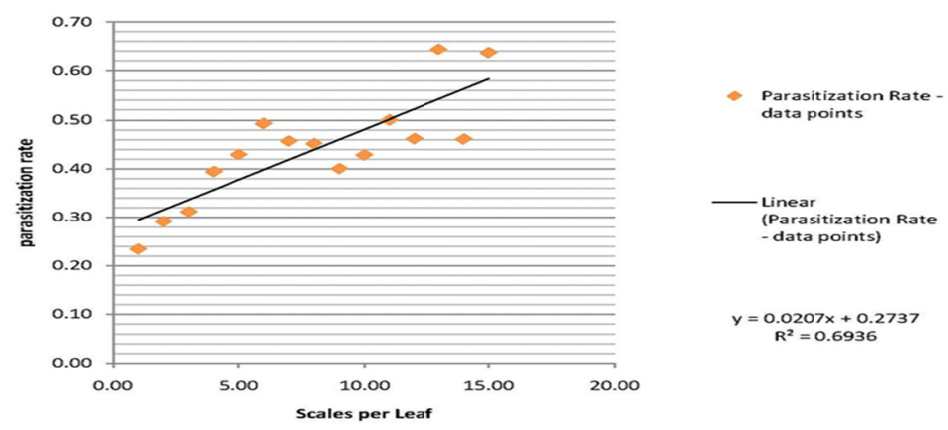

Figure 6. Parasitization rate vs. Number of scales per leaf

This observation might be due to the possibility that a higher density of scales could attract more parasites, or perhaps once a parasite lands on a scale its subsequent expansion will depend on the opportunity to infect adjacent scales. The probability that the first parasite will settle on a scale on leaves with various scale densities was calculated using Equation (5).

In theory it is possible for the probability of infection to vary with $\mathrm{n}$, the number of scales on a leaf. For example, if leaves with large $\mathrm{n}$ are those that are more accessible both to wasps and to spores, the above probability might increase with $\mathrm{n}$. Or if a questing wasp detects some pheromone from the scales it might find leaves with many scales more easily. However, Table 9 shows that the probability of infection by the first, second and third parasite is all independent of $\mathrm{n}$. Therefore where there are insufficient leaves with a larger number of scales, the estimate from $n=1$ can be used, and $\mathrm{p}$ is simply the fraction of leaves with one scale that are parasitized. The same result was 
obtained for both fungi Sphaerostilbe auranticola and the wasp. The number of observations for the other two fungi was too small to carry out a similar analysis.

Table 9. Probability of sequential infection as a function of scale number

\begin{tabular}{clll}
\hline $\begin{array}{c}\text { Number of scales(N) } \\
\text { (Sessile stages) }\end{array}$ & Pi1 & Pi2 & Pi3 \\
\hline 1 & 0.235 & ---- & ---- \\
2 & 0.234 & 0.407 & --- \\
3 & 0.224 & 0.314 & 0.413 \\
4 & 0.246 & 0.317 & 0.385 \\
5 & 0.247 & 0.327 & 0.320 \\
6 & 0.241 & 0.367 & 0.420 \\
7 & 0.205 & $*$ & $*$ \\
8 & 0.262 & $*$ & $*$ \\
9 & 0.219 & $*$ & $*$ \\
10 & 0.200 & $*$ & $*$ \\
& & & \\
Mean & 0.231 & 0.346 & 0.385 \\
\hline
\end{tabular}

Pi1 - probability of first infection;

Pi2 - probability of second infection;

Pi3 - probability of third infection;

*The numbers were too small for the calculations.

The probability that a second parasite infests scales, pi2, given that a first infection already exists was calculated using equation (6). Table 9 shows that although this probability is higher than the probability of infection with the first parasite it is also independent of scale density. The same can be said for pi3. In summary: it was observed that pi3 $>$ pi $2>$ pi1. It seems that pi is random and once the first parasite settles it needs just an adjacent scale to propagate and not the entire foci.

The estimate of pi 2 includes both external infection probabilities pil and the additional probability due to sharing a leaf. Therefore the additional probability is estimated by pi 2 - pi1. This is equivalent to the increased risk for a scale when it shares its leaf with other scales. A similar argument can be used to ask about the conditional probability of infecting a third scale given that two are already infected on a given leaf. A separate analysis for Sphaerostilbe auranticola, the most prevalent fungus shows a similar pattern (Table 10) and the same was observed for the wasp (Table 11):

Table 10. Probability of sequential infection by Sphaerostilbe auranticola

\begin{tabular}{cccc}
\hline $\begin{array}{c}\text { Number of scales (n) } \\
\text { (Sessile stages) }\end{array}$ & Pi1 & Pi2 & Pi3 \\
\hline 1 & 0.175 & ---- & ---- \\
2 & 0.159 & 0.345 & --- \\
3 & 0.157 & 0.290 & 0.296 \\
4 & 0.177 & 0.280 & 0.351 \\
5 & 0.174 & 0.328 & 0.288 \\
6 & 0.162 & 0.251 & 0.212 \\
7 & 0.140 & 0.215 & $*$ \\
8 & 0.182 & $*$ & $*$ \\
Mean & 0.166 & 0.285 & 0.286 \\
\hline
\end{tabular}

*The numbers were too small for the calculations. 
Table 11. Probability of sequential infection by the wasp

\begin{tabular}{cccc}
\hline $\begin{array}{c}\text { Number of scales(n) } \\
\text { (Sessile stages) }\end{array}$ & Pi1 & Pi2 & Pi3 \\
\hline 1 & 0.072 & ---- & ---- \\
2 & 0.086 & 0.260 & --- \\
3 & 0.101 & 0.164 & 0.272 \\
4 & 0.085 & 0.134 & 0.123 \\
5 & 0.108 & 0.173 & 0.279 \\
6 & 0.079 & 0.178 & 0.205 \\
Mean & 0.089 & 0.182 & .220 \\
\hline
\end{tabular}

\subsection{Survival Through the Stages}

The number of scales in each life stage reflects the duration of that stage, survival from previous stages, and survival during that stage. As the scale progressed through the various developmental stages there was a decrease in abundance as seen from the ratios among the stages as presented in Table 12 (the calculations takes into account that a crawler lives for one day and the other stages last approximately 20 days).

Table 12. Survival ratios through the stages across trees

\begin{tabular}{cccc}
\hline Tree & Nymph/crawler & Female/nymph & Fert/Female \\
\hline 1 & 0.077 & 0.416 & 0.654 \\
2 & 0.068 & 0.467 & 0.781 \\
3 & 0.074 & 0.334 & 0.792 \\
4 & 0.078 & 0.424 & 0.475 \\
5 & 0.062 & 0.523 & 0.522 \\
Aggregated & 0.073 & 0.486 & 0.579 \\
\hline
\end{tabular}

The greatest loss happens at the transition between crawlers to the nymph stage. Once the scale survived through the nymph stage there was good survival to the adult one. Half of the nymphs would expect to become females and the observed ratio of . 49 means that there was a $98 \%$ survival. Of those, $58 \%$ survived and became fertilized. The above results indicate the most of the loss occurs in the crawler and nymphal stages. Past the nymphal stage there is almost un-interfered progression to completion of the life cycle.

The data in Table 12 served as the basis for comparing the daily survival probabilities of the scale at its different developmental stages. For the calculations it was assumed that scales exist as crawlers for only one day, and that it takes twenty days to progress from one stage to another in the subsequent stages (Metcalf \& Flint, 1962). Thus, accounting for the different average length of survival, the twentieth roots of the ratios female/nymph and fertile/female were taken (Table 13).

Table 13. Daily survival of the scale stages

\begin{tabular}{lc}
\hline Stage survival & Probability \\
\hline Crawlers & 0.073 \\
Nymphs & 0.999 \\
Females & 0.973 \\
\hline
\end{tabular}




\section{Discussion}

If a population varies greatly during the annual cycle and yet remains within bounds over the years, then some processes of regulation must be at work. Either fecundity decreases or mortality or emigration increases with density. Although reproduction does depend on seasonal conditions, no evidence of it varying across locations was found despite density differences.

The coccid scale Lepidosaphes gloverii is common on orange trees, with $61 \%$ of the leaves having one or more scale insect. The distribution on leaves was not uniform across microhabitats. The patterns were somewhat different when only live scales or total scales (live scales plus parasitized scale) were examined. Total scales did not differ among cardinal points, but because of uneven parasitization the live scales were not equally abundant. On the other hand, total scales differed among strata in the tree, but after uneven parasitization the difference disappeared. There was variation among trees, with the number of scales per leaf being correlated with the vigor of growth of new flushes, providing better nutrient conditions. Scales were more abundant on the upper than the lower surface of leaves and there was a tendency to prefer the middle leaves of a flush.

The population dynamics of the scale depended on its interaction with its environment. There was marked seasonal variation in recruitment (fecundity times crawler survival), associated with the seasonal cycle of the trees. The mineral content of the leaves varies seasonally and young leaves are produced in a few flushes peaking in late autumn (Figure 1); although no physiological data was collected for the trees their condition can be inferred from the number of leaves counted in each observation period. The seasonal distribution of scales coincided with that of the scales (Figure 3). New foci are formed by the crawlers, the only mobile stage in the life cycle of the scale. In fact results show that $80 \%$ of the emerging crawlers leave the site of birth preferring the upper side of the leaf over the lower one, by four folds. The parasitic species differ among themselves in microhabitat locations (Table 14).

Table 14. Parasites preferred location

\begin{tabular}{lcccc}
\hline Parasite & Preferred tree & Preferred surface & Preferred stratum & Preferred direction \\
\hline$P C$ & 5 & Upper & 2 & South \\
$M D$ & 5 & Upper & 2 & West \\
$S A$ & 5 & Upper & 1 & West \\
$A S P I$ & 3 & Lower & 3 & South \\
\hline
\end{tabular}

This, both, reduces potential competition among the natural enemies of the scale and increases the coverage of the microhabitats in the orchard. In particular the two most abundant parasites the fungus Sphaerostilbe auranticola and the wasp Aspidiotiphagus sp. prefer to inhabit different locations. Furthermore, they are introduced and reach their peaks at different times, again to minimize competition and increase the likelihood of parasitization. In accordance mathematical models have predicted that biological control is most effective when natural enemies are heterogeneous in their spatial distribution (Beddington, Free, \& Lawson, 1978).

Infection by fungi or parasitoids can occur in two ways. The first is introduced from the outside. A spore drifting in the air can land on a leaf and germinate, penetrating a scale. Similarly a wasp searching for a host in the foliage may find a leaf with scales and deposit her eggs in the scale.

The second type of infection occurs within a leaf. If a scale is infected, crawlers can drag spores around the leaf surface infecting other scales. Or a wasp finding a host on a leaf may be encouraged to continue looking. Therefore the probability of a second scale becoming infected on a leaf once a first scale has been infected may be greater.

The observation from Table 9, that pi3 $>$ pi2 $>$ pi1, indicates that pin is random and once the first parasite settles it needs just an adjacent scale to propagate and not the entire foci. The estimate of pi2 includes both external infection probabilities pil and the additional probability due to sharing a leaf. Therefore the additional probability is estimated by pi2 - pi1. This is equivalent to the increased risk for a scale when it shares its leaf with other scales. A similar argument can be used to ask about the conditional probability of infecting a third scale given that two are already infected on a given leaf.

Indeed the mortality due to parasitization of a scale increases with the number of scales on the same leaf. However, aggregated scales do not attract parasites; that is, the probability of the first scale on a leaf being infected by a fungal spore or parasitized by the wasp is independent of the number of scales on the leaf (Tables 10,11,12). But once one scale is parasitized the risk to the others increases linearly with the number of scales (Figure 6). 
The scale population is aggregated more than would be expected from a random Poison distribution. This aggregation is most pronounced among crawlers and diminishes with life stage. A Taylor regression for aggregation across leaves showed a marked difference when parasite was included in the analysis suggesting that parasitization increases with aggregation. This is consistent with the observed parasitization rates which increase with the number of scales on the leaf. The aggregation increases mortality due to parasitization and is therefore one mechanism of density dependent regulation.

Scale insects experience mortality also due to predators, and mechanical impacts, for instance when wind and heavy rains knock the crawlers off the leaves or entire leaves of the trees. It is reasonable to think that the scales on the upper surface of the leaf are more vulnerable than the ones on the lower one, since the ratio of scale abundance between the surfaces decreases as the scale progresses through its developmental stages (Table 3 ). The analysis of survival through the stages showed that only about $7 \%$ of the crawlers survived to become live nymphs (Table 12). The nymphs that survived had a very high daily survival probability and a high cumulative probability to molt into adults. This probability is higher than the probability of becoming a fertile female ( 0.97 vs. 0.58$)$ (Table 12 and Table 13). Even if the risk of death were the same for these two stages, the probability of transition from female to a fertilized female depends also on the chance of being fertilized. Observations are consistent with results obtained in studies with the lesser snowy scale on grapefruit, in which mite predators are a major source of early mortality in the crawler stage; then fungi predominate in the nymphs and finally parasitoids in the later stages (Miriam Fernandez, personal communication). Although the daily survival probabilities of the scale at its various stages (except for the crawlers) is very high, the cumulative survival is a lot lower due to a gradual loss (Table 12 and Table 13).

Figure 7a. Loops for interactions among Scales, Natural enemies and Pesticides

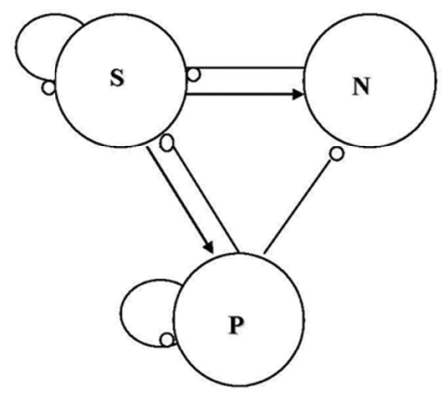

Figure 7b. Analysis for interactions among Scales, Natural enemies and Pesticides

\begin{tabular}{|c|c|c|c|}
\hline & S & N & P \\
\hline S & 0 &,+- & + \\
\hline N & - & + & - \\
\hline P & + & - & + \\
\hline
\end{tabular}

The Scales $(\mathrm{S})$, their natural enemies $(\mathrm{N})$ and pesticides $(\mathrm{P})$ are linked with arrows indicating either a direct positive effect $(\stackrel{\longrightarrow}{\longrightarrow})$ or a negative one: $(\longrightarrow$ ). The figure illustrates how the existence of scales prompts the application of pesticides which in turn reduce the scale population. S and P. Note that the pecticide has a negative effect on both the vector and the natural enemies. An impact from the outside on a particular variable will perculate to the others through the network of interactions. A qualitative mathematical analysis of such a system will result in the table, summarizing the effect perturbation each of the variables will have on the others (Puccia and Levins 1985). For example, in the last row we examine the effect of adding pesticides to the system has on the $\mathrm{S}, \mathrm{N}$ and $\mathrm{P}$ itself. We that adding pesticides will result in an increase in the S population, in reduction of its $\mathrm{N}$ and in an increase in Pesticide, polluting the environment

Figure 7. Complex system analysis for scales, natural enemies and pesticides interactions

\section{Conclusion}

Findings indicate that the scale population is kept in check by seasonally varying recruitment which is offset by mortality that responds to population increase through the buildup of several parasitic species with overlapping but distinct micro habitat preferences, the increased aggregation of scales on leaves with population growth, and the increase in mortality of scales when they are aggregated. This work makes it clear that the old debates between "environmental" determination (Andrewartha \& Birch, 1954) and density dependent regulation as espoused by Nicholson and Bailey (Nicholson \& Bailey, 1935) are both 
operative simultaneously as proposed by others (Levins \& Schultz, 1996; Price, 1991). The mechanisms of pest regulation in the context of a multi species community as presented in this paper explains the overall theoretical result obtained through loop analysis of a complex system which also includes the addition of pesticides (Figure 7). According to this analysis, the use of pesticides might be counter productive and perhaps the best intervention as not to intervene (Awerbuch, Kisezewski, \& Levins, 2002).

\section{Acknowledgements}

This paper is dedicated to our friend and colleague Hiraldo Lima.

This work was carried out while Maria del Carmen Perez Hernandez led the Institute of Frutales, Ministry of Agriculture, Havana, Cuba. She was an inspiration to all of us. We also want to thank The David Rockefeller Center for Latin American Studies which under the supportive leadership of Dr. John Coatsworth, our collaborations with Cuban colleagues was made possible. We thank Hyung Park for helping edit the manuscript.

\section{References}

Altieri, M. A. (1999). The ecological role of biodiversity in agroecosystems. Agriculture, Ecosystems \& Environment, 74(3), 19-31. http://dx.doi.org/10.1016/S0167-8809(99)00028-6

Andrewartha, H. G., \& Birch, L. C. (1954). The distribution and abundance of animals. University of Chicago Press.

Awerbuch, T., Kisezewski, A., \& Levins, R. (2002). Surprise, nonlinearity and complex behavior. In Martens \& Mcmichael (Eds.), Health Impacts of Global Environmental Change: Concepts and Methods (pp. 96-102). Cambridge, England: Cambridge Universy Press.

Beddington, J. R., Free, C. A., \& Lawson, J. H. (1978). Characteristics of successful natural enemies in models of biological control of incest pests. Nature, 273, 513-519. http://dx.doi.org/10.1038/273513a0

Bianchi, F. J. J. A., Booij, C. J. H., \& Tscharntke, T. (2006). Sustainable pest regulation in agricultural landscapes: a review on landscape composition, biodiversity and natural pest control. Proceedings of the Royal Society, 273(1593), 1715-1727. http://dx.doi.org/10.1098/rspb.2006.3530

Dean, A. G., Dean, J. A., Burton, A. H., \& Dicker, R. C. (1990). Epi Info, Version 5: a word processing, database and statistics program for epidemiology on microcomputers. USD, Incorporated, Stone Mountain, Georgia.

Greathead, D. J. (1990). Crawler behavior and dispersal. In D. Rosen (Ed.), Armored scale insects: their biology, natural enemies and control. vol. A. Elsevier, Amsterdam.

Landis, D. A., Wratten, S. D., \& Gurr, G. M. (2000). Habitat Management to Conserve Natural Enemies of Arthropod Pests in Agriculture. Annual Review of Entomology, 45, 175-201. http://dx.doi.org/10.1146/annurev.ento.45.1.175

Levins, R., \& Schultz, B. B. (1996). Effects of density dependence, feedback, and environmental sensitivity on correlations among predators, prey, and plant resources: models and practical implications. Journal of Animal Ecology, 65, 802-812. http://dx.doi.org/10.2307/5678

Lotus 1-2-3, Release 3. (1988). Lotus Development Corporations. Cambridge, MA.

Luck, R. F., Allen, J. C., \& Baasch, D. (1980). A systems approach to research and decision-making in the citrus ecosystem. In C. B. Huflacker (Ed), New technology of pest control (pp. 365-396). Wiley-Interscience. John Wiley and Sons, Inc.

Metcalf, C. L., \& Flint, W. P. (1962). Destructive and useful insects; their habits and controls. McGraw Hill.

Nestel, D., Cohen, H., Saphir, N., Klein, M., \& Mendel, Z. (1995). Spatial distribution of scale insects: comparative study using Taylor's power law. Environmental Entomology, 4(3), 506-512.

Nicholson, A. J., \& Bailey, V. A. (1935). The balance of animal populations. Proceedings of the Zoological Society of London, 3, 551-598.

Price, P. W. (1991). Darwinian methodology and the theory of insect herbivore population dynamics. Annals of the Entomological Society of America, 84, 465-473.

Strong, D. (1989). Density independence in space and inconsistent temporal relationships for host mortality caused by a fairfly parasitoid. Journal of Animal Ecology, 58, 1065-1076. http://dx.doi.org/10.2307/5142 
Taylor, L. R., Woiwod, I. P., \& Perry, J. N. (1978). The density-dependence of spatial behavior and rarity of randomness. Journal of Animal Ecology, 47, 383-406. http://dx.doi.org/10.2307/3790

Wilby, A., \& Thomas, M. B. (2002). Natural enemy diversity and pest control: patterns of pest emergence with agricultural intensification. Ecology

Letters, $5(3)$, 353-360. http://dx.doi.org/10.1046/j.1461-0248.2002.00331.x

\section{Copyrights}

Copyright for this article is retained by the author(s), with first publication rights granted to the journal.

This is an open-access article distributed under the terms and conditions of the Creative Commons Attribution license (http://creativecommons.org/licenses/by/3.0/). 